\title{
Classification of Yoga Postures-A Physical Medicine Approach
}

\author{
Guruprasad Venkateshwara ${ }^{1}$ and Rajiv Singh ${ }^{2 *}$ \\ ${ }^{1}$ Salford Royal Hospital and Central Manchester Teaching Hospitals, UK, \\ ${ }^{2}$ School of Health and Related Research University of Sheffield, UK
}

Submission: November 13, 2017; Published: November 21, 2017

*Corresponding author: Rajiv Singh, Consultant and Senior Lecturer in Rehabilitation Medicine, School of Health and Related Research University of Sheffield and Sheffield Teaching Hospitals, 30 Regent St, Sheffield S1 4DA, Sheffield S5 7AU, UK, Tel: +44-1142715651; Email: rajiv.singh@sth.nhs.uk

\begin{abstract}
Objective: To classify the Yoga postures according to the type of exercise format, muscle contractions and the intensity of exercise.

Results: Yoga postures as a component of physical fitness has been practised over millennium. Its origins are traced back to India and it has now gained acceptability worldwide. Even though the modern medicine agrees it as an exercise format, a proper acceptable scientific classification of the yoga posture is not yet attempted. There are some classification available based to movement pattern, position and site involved. But a physiological classification based on the type of muscle contractions, intensity of exercise and type of exercise format is not available.
\end{abstract}

Conclusion: The classification attempted here would help in simplifying and classify the yoga postures according to muscle activity, exercise format and grades of intensity would make it more easy and understandable for specialists in Modern medicine.

Keywords: Yoga; Exercise therapy; Muscle stretching exercises; Resistance training; Physical conditioning human

\section{Introduction}

Yoga postures are noted to have origins in India around 5000 years back and it is noted to encompass the concepts of physical postures, breathing exercises and meditation. The postures were named on animals, flowers or spiritual form from which humans found associations.

Over the couple of centuries there have been a lot scientific developments in the western world and the exercise science has taken its shape as a separate speciality. The whole set of exercises are classified on various contexts like muscle physiology, cardiac effects, either goal oriented or therapeutic model for certain diseases. Yoga postures have been on the back bench from the main stream fitness model for the past few centuries due to many reasons. Over the last few decades the Yoga has started to re-emerge from its quiescence as the contemporary system of exercises model with noted effects on both body and mind. Over the past few decades yoga has entered the western society mainly as an exercise format rather than its holistic approach.
The benefits of yoga documented in literature are mainly in development of confidence, physical fitness, anger management, depression but it still yet to be proved as a stand-alone curative modality of treatment [1]. There is no universally accepted classification of the yoga postures in the modern medicine which can be used for communication among specialists in the related field. The studies pertaining to the biomechanics of the yoga postures are also very limited. Thus many of the claimed benefits of individual yoga postures have not been sufficiently backed up by internationally acceptable model of evidence. The number of Randomised control trials (RCT) is still very limited. The biomechanical analysis of each yoga postures has not yet been completed. The very physical exercises concept of yoga postures have not been fully comprehended due to lack quality data and non-availability of universal classification system for the purpose of communication.

The other benefit of having a scientific classification is the fact that a classification would also help in understanding the 
physiology and biomechanics in the medical language so as to advice about the precautions to be taken in chronic medical conditions. As the number of people doing yoga increases, so as the number of injuries related to it. Nearly $30 \%$ of the yoga attendees are noted to have some side effects [2]. The common adverse incidents noted are musculoskeletal injuries, low back pain, myalgia, worsening of glaucoma, keratectasia, central retinal vein occlusion, and progressive optic neuropathy and pneumothorax.

One of the starting points would be to classify the Physical component of yoga postures in the internationally agreeable language for the means of communicating among professionals. This would enable for further therapeutics and research studies.

The classifications currently available in literature are

a. Posture based classification like standing, sitting or lying down postures.

b. Muscle group based classification like extensors, flexors etc.

c. Site based classification like upper limb, lower limb, spinal etc.

There is of course a lack of a universally acceptable classification of the yoga postures for communication among the mainstream physicians and specialists of PMR or exercise science. So one of the scientific way of classifying them is based on the type of muscle contractions (like isometric or isotonic contractions), type of exercise pattern (stretching, aerobic exercise) and the intensity of exercise based on the group of muscle activity (mild, moderate, severe). Some of the above nomenclature has been used in some publications [3] but there has been no formal approach to classify the yoga postures in medical communications format.

Currently the modern medicine specialists struggle to prescribe the yoga postures due to lack of education and training. So a development of a classification would benefit them in understanding and prescribing Yoga in future.

\section{Classification}

The muscular contractions in most of the yoga postures would be isometric contractions. The yoga exercise involves stretching of various joints at the simplest. So it would be simple to classify them depending on the number of muscles contracted in each posture.

There can be associated isometric contractions of the muscles which could be against gravity or gravity eliminated depending on the posture. As the complexity of the postures increase the intensity of muscle contractions increase thus consuming more calories. So it becomes imperative to classify them according to the intensity of muscle contractions. As the muscles work in groups, it is wise to consider the number of groups involved to stratify the intensity. This would help while doing future research to specify the grade and intensity as the level of energy consumption can vary among different postures [4].

The postures can also be classified based on the groups of muscles undergoing isometric contractions, this would help in understanding the difficulty in attaining a posture, the intensity of effort needed to maintain the posture and of course it would give an idea about the energy expenditure and calorie consumption in attaining and maintaining the posture for specific time.

The classification can be as follows:

I. Static Stretching exercise (SE)

II. Static Stretching + Isometric exercise (SIE)

a. GRADE I- Mild intensity (up to 2 groups of muscles)

b. GRADE II- Moderate intensity (3- 4 groups of muscles)

c. GRADE III- Strenuous (more than 5 group of muscles)

III. Dynamic stretching and Aerobic exercise (AE)

a. Sun salutation set of postures (SS)

b. Other defined set of asana's (OS)

This type of classification would enable the professional of the related field to quickly localise the posture to a particular category, understand the level of physical strength, exercise endurance capacity and also gross calorie consumption of such a posture. This would also help for further researchers to standardise each posture and its parameters like heart rate variability, VO2 max, blood pressure, hormonal levels, and objective measures of health like improvement in functional levels.

\section{Discussion}

According to the American College of Sports Medicine (ACSM) guidelines an average adult need

a. Moderate-intensity cardio respiratory exercise training for $\geq 30 \mathrm{~min} /$ day for $\geq 5$ days/week, vigorous-intensity cardio respiratory exercise training for $\geq 20 \mathrm{~min} /$ day for $\geq 3 \mathrm{~d} /$ week or a combination of moderate-and vigorous-intensity exercise.

b. Resistance exercises for each of the major muscle groups, involving balance, agility and coordination for 2-3 days/week.

c. Flexibility exercises for each the major muscle-tendon groups $\geq 2$ days/ week. 
If we classify the postures according to the above presented system it would help us to associate it type of ACSM exercises guidelines. This in future would also help in integration and collaboration for future research and exercise prescription. Of course it is understood that the above classification might not be the comprehensive one, but it would definitely help in thinking towards a scientific approach for yoga posture classification.

\section{Conclusion}

Yoga postures should be able to provide all the above three categories of exercises as per the above classification even though the duration and intensity can vary depending on each individual. This type of classification is an effort to classify the yoga postures based purely on the physical effects which would enable professional to understand the various parameters of exercise assessment. It would also be helpful in documentation as a grade of exercise and for inter-professional communication of the information.

\section{References}

1. Bussing A, Michalsen A, Khalsa S, Telles S, Sherman K (2012) Effects of Yoga on Mental and Physical Health: A Short Summary of Reviews Evidence-Based Complementary and Alternative Medicine 2012(165410): 7 .

2. Matsushita T, Oka T (2015) A large-scale survey of adverse events experienced in yoga classes. Biopsychosoc Med 18(9): 9.

3. Karbandi S, Gorji MA, Mazloum SR, Norian A, Aghaei N (2015) Effectiveness of Group Versus Individual Yoga Exercises on Fatigue of Patients with Multiple Sclerosis. N Am J Med Sci 7(6): 266-270.

4. http://www.acsm.org/about-acsm/media-room/newsreleases /2011/08/01/acsm-issues-new-recommendations-onquantity-and-quality-of-exercise

\section{Your next submission with Juniper Publishers will reach you the below assets}

- Quality Editorial service

- Swift Peer Review

- Reprints availability

- E-prints Service

- Manuscript Podcast for convenient understanding

- Global attainment for your research

- Manuscript accessibility in different formats ( Pdf, E-pub, Full Text, Audio)

- Unceasing customer service

Track the below URL for one-step submission https://juniperpublishers.com/online-submission.php 